\title{
SABERES, TRABALHO E ALIMENTAÇÃO PARA A LIBERDADE: PRÁXIS EXTENSIONISTA EM UM CONTEXTO PRISIONAL
}

\section{KNOWLEDGE, WORK AND FOOD FOR FREEDOM: THE OUTREACH PRAXIS IN A PRISON CONTEXT}

\author{
Everton Luiz Simon* \\ ORCID: https://orcid.org/0000-0002-1227-4813 \\ Hosana Hoelz Ploia** \\ ORCID: https://orcid.org/0000-0002-7043-060X \\ Cheron Zanini Moretti*** \\ ORCID: https://orcid.org/0000-0002-6297-3129
}

\section{Resumo}

O presente artigo busca apresentar reflexões a respeito das experiências de extensão universitária, vivenciadas em um complexo prisional na cidade de Santa Cruz do Sul. Busca-se refletir a relação entre alimentação prisional, saberes e trabalho dos apenados permitidos a participar das atividades de produção de alimentos na cozinha ${ }^{i}$. Metodologicamente, através da pesquisa bibliográfica, procurou-se levantar e analisar produções científicas que versam sobre a temática do direito humano ao trabalho, à ressocialização e à alimentação em complexos prisionais. As experiências in loco, mediatizadas pelas técnicas da observação participante e diário de campo, permitiram acompanhar, cooperar e estabelecer relações entre os processos e os seus significados para os sujeitos envolvidos. A partir da identificação de saberes populares e demais manifestados ou desenvolvidos ao longo do período de extensão, ressaltou-se o protagonismo dos trabalhadores na cozinha, pela valorização de sua habilidade produtiva e a mediação de reflexão própria sobre a realidade.

Palavras-chave: Segurança alimentar; Direitos Humanos; Privação de liberdade; Saberes populares; Extensão universitária.

Data recebimento: $28 / 06 / 2021$

Data de aceite: $24 / 09 / 2021$

\begin{abstract}
This article aims to provide some reflections about the outreach experiences carried out at a prison in Santa Cruz do Sul. It considers the link between the food served in prisons, knowledges and the labor of inmates who partake in the food production activities at the prison kitchen. Through bibliographic research, it was collected and analysed data about human rights concerning the work, resocialization and food served in prisons. The in-site experiences, mediated by participant observation and field diary, allowed follow-up, cooperation and connection among the processes and their meanings to the individuals involved. From the recognition of popular knowledges and others shown or developed throughout the outreach activities, it is possible to highlight the protagonism of the prisoners who work in the kitchen due to the importance given to their productive ability and their self-awareness about the reality in which they live.
\end{abstract}

Keywords: Food safety; Human Rights; Deprivation of liberty; Popular knowledges; University extension.

\footnotetext{
* Professor da Universidade de Santa Cruz do Sul (UNISC), Santa Cruz do Sul - RS, Brasil. E-mail: evertonsimon@gmail.com

** Aluna de Graduação da Universidade de Santa Cruz do Sul (UNISC), Santa Cruz do Sul - RS, Brasil. E-mail: hhploia@mx2.unisc.br

** Professora da Universidade de Santa Cruz do Sul (UNISC), Santa Cruz do Sul - RS, Brasil. E-mail: cheron.moretti@gmail.com
} 


\section{Introdução}

Este artigo procura apresentar os processos relacionados à produção de alimentos e de saberes no trabalho no complexo prisional de Santa Cruz do Sul, Rio Grande do Sul. As discussões pertinentes à alimentação em unidades penitenciárias são de grande importância, pois evidenciam a necessidade de oferta de uma alimentação adequada em quantidade e qualidade para a manutenção da vida, enquanto direito fundamental do sujeito em privação de liberdade. Assim, o foco principal deste artigo está em identificar e analisar a relação entre saberes, trabalho e alimentação dos apenados que atuam nas atividades de produção de alimentos na cozinha desse complexo prisional, e em compreender os sentidos de uma efetiva ressocialização pelos seus saberes.

A realização deste texto é resultado das experiências de extensão universitária do Programa Nacional de Reorientação da Formação Profissional em Saúde - PRÓ-SAÚDE, realizadas por estudantes do curso de Gastronomia e Nutrição da Universidade de Santa Cruz do Sul - UNISC, através do subprojeto alimentação e saúde, no Presídio Regional de Santa Cruz do Sul, Rio Grande do Sul. Tais atividades extensionistas decorrem de demandas apresentadas pelo Conselho da Comunidade ${ }^{\mathrm{ii}}$ ao Programa Nacional de Reorientação da Formação Profissional em Saúde - PRÓ-SAÚDE da Universidade de Santa Cruz do Sul. A partir de registros de demandas relacionadas aos problemas de insegurança alimentar e o excessivo desperdício de alimentos resultante do processo de produção ao consumo, no presídio regional de Santa Cruz do Sul, busca-se minimizar os problemas identificados e colaborar com a garantia de Direito Humano à Alimentação Adequada.

É relevante mencionar que a origem das universidades comunitárias brasileiras se relaciona com as práticas comunitárias e extensionistas, vinculadas à formação de sujeitos coletivos, lugar de referência para a qualificação do ensino e da pesquisa. No estado do Rio Grande do Sul, nascem especialmente de movimentos comunitários que buscam fortalecer as experiências de seu entorno geográfico, "a partir de projetos de inserção e de engajamento que oferecem demandas e são também demandadas pelos sujeitos dialógicos". (MENESES, MORETTI, 2018, p. 31). Assim, de acordo com Fernandes (2011), extensão é indispensável para a constituição de cidadania, uma vez que a "equação" ensino, pesquisa e extensão se promove através de integração: "a extensão é uma ação pedagógica que contribui para a formação de profissionais cidadãos tecnicamente competentes e comprometidos com uma sociedade mais justa". (FERNANDES, 2011, p. 141).

A boa qualidade da alimentação em complexos prisionais é uma das principais dificuldades de se obter, especialmente por parte do Estado, enquanto provedor de condições básicas de saúde e bem-estar para os detentos. Essa problemática é realçada ao se considerar o Plano Nacional de Saúde no Sistema Penitenciário, o qual aponta que o cárcere no Brasil apresenta fatores como superlotação, pouca ventilação e condições sanitárias adversas, que 
não contemplam as ações de promoção, prevenção e atenção integral à saúde da pessoa privada de liberdade (BRASIL, 2014; SOUSA et al., 2013).

As reflexões de pesquisa, de caráter qualitativo, organizaram-se, primeiramente, através das técnicas da pesquisa bibliográfica e documental, ao levantar e analisar produções científicas que versam sobre a temática do direito humano ao trabalho, à ressocialização e à alimentação em complexos prisionais. As experiências in loco realizadas no complexo prisional, uma vez por semana, desde 2018, através de atividades extensionistas, apoiaram-se em técnicas de observação participante e em registros em diário de campo. A observação participante possibilita a integração do/da pesquisador/a com o contexto e o ambiente pesquisado, permitindo acompanhar, cooperar e estabelecer relações com os processos e os significados entre os sujeitos envolvidos, com o objetivo de realizar a pesquisa (OLIVEIRA, 2020).

O diário de campo, por sua vez, como instrumento de apoio, permitiu registrar, descrever e anotar os acontecimentos e as observações durante a estada no campo de pesquisa e de extensão (OLIVEIRA, 2014). Para a organização e análise dos dados registrados no diário de campo, recorreu-se à metodologia da Análise Textual Discursiva (ATD), proposta por Roque Moraes e Maria do Carmo Galiazzi (2016, p. 134), a qual é entendida como um processo de "desconstrução, seguido de reconstrução" dos registros, produzindo, a partir disso, "novos entendimentos sobre os fenômenos e discursos investigados". De acordo com estes/as autores/ as, a metodologia trabalha com significados construídos, ao analisá-los e compará-los, e propõese a descrever e a interpretar os múltiplos sentidos que a leitura e a interpretação do conjunto de textos podem revelar. Por questões éticas, nenhuma pessoa privada de liberdade será mencionada ao longo da escrita.

O texto está organizado em dois tópicos, além desta introdução e das considerações finais. O primeiro retrata, através de pesquisa bibliográfica, a política do Direito Humano à Alimentação Adequada em complexos prisionais, a partir de uma perspectiva gastronômica. Em seguida, procura-se apresentar a realidade dos processos de preparo e distribuição da comida no complexo prisional de Santa Cruz do Sul e identificar os saberes daqueles que a produz. A partir disso, buscou-se, por fim, destacar as relações entre alimentação e saberes no trabalho e na ressocialização, com influência direta sobre os trabalhadores apenados.

\section{Alimentação e Direitos Humanos: uma perspectiva gastronômica em complexos prisionais brasileiros}

A constituição de Direitos Humanos como elementos obrigatórios para garantir vida digna, livre e igualitária a todos os seres humanos surge da historicidade das lutas por direitos por parte dos/as oprimidos/as e excluídos/as no âmbito social. Segundo Villas Bôas e Soares (2020), a necessidade do estabelecimento do Direito Humano parte de contextos de opressão, 
humilhação e violação da dignidade, intensificadores de desigualdades sociais e da inércia humana quanto ao próprio crescimento. Para tanto, os direitos humanos se caracterizam como "universais, indivisíveis, inalienáveis, interdependentes e interrelacionados em sua realização" (LEÃO, 2013, p. 25). Na perspectiva de Villas Bôas e Soares (2020, p. 20),

constituem um conjunto de faculdades e instituições que, em cada momento histórico, concretizam as exigências da dignidade, da liberdade, da igualdade humana, as quais exigem reconhecimento positivo pelos ordenamentos jurídicos, em nível nacional e internacional.

Desse modo, a determinação do acesso total aos benefícios previstos pelos direitos humanos é de responsabilidade do Estado, assim como a concretização da sua manutenção. Parte-se, então, do mínimo ao máximo existencial provido ao/à cidadão/ã, mediante os fundamentos da justiça, liberdade e paz igualitárias (VILLAS BÔAS; SOARES, 2020). Em busca da segurança da dignidade da pessoa, a garantia dos seus direitos sociais resulta no seu desenvolvimento, imprescindível para a humanidade.

No viés dos direitos humanos há a alimentação, prevista na Constituição Federal, em seu Artigo 6", o qual garante "a educação, a saúde, a alimentação, o trabalho, a moradia, o transporte, o lazer, a segurança, a previdência social, a proteção à maternidade e à infância, a assistência aos desamparados" (BRASIL, 2015) como direitos sociais fundamentais para todos/ as os/as integrantes da sociedade brasileira. Da mesma forma, o Artigo $25^{\circ}$ da Declaração dos Direitos Humanos prevê que

\footnotetext{
todo ser humano tem direito a um padrão de vida capaz de assegurar a si e à sua família: saúde, bem-estar, inclusive alimentação, vestuário, habitação, cuidados médicos e serviços sociais indispensáveis e direito à segurança em caso de desemprego, doença, invalidez, viuvez, velhice, ou outros casos de perda dos meios de subsistência em circunstâncias fora de seu controle. (UNICEF, 1948, s.p.).
}

Sousa et al. (2019, p. 1668) identificam que, "no Brasil, a alimentação como direito social foi assegurada a partir do ano de 2010, com a Emenda Constitucional n ${ }^{\circ}$ 644, e de acordo com o Conselho Nacional de Segurança Alimentar e Nutricional (CONSEA)". Ainda, é vigente o Fórum Brasileiro de Segurança Alimentar e Nutricional, assim como a Política Nacional de Segurança Alimentar e Nutricional (PNSAN), desde 2010, constituída pela Lei Orgânica de Segurança Alimentar e Nutricional (LOSAN). (LEÃO, 2013). Todas essas instituições e suas respectivas orientações em Lei prezam por assegurar a saúde pública através de medidas que demandam a oferta de comida adequada a toda a população, sem distinção, pelo Estado mantenedor. 
As pessoas privadas de liberdade, por sua vez, são contempladas no mesmo ínterim, e, portanto, cabe ao Estado viabilizar, em complexos prisionais, uma alimentação adequada às diferentes particularidades nutricionais e segura em termos de promoção de saúde pública, Com relação a isso, a Lei de Execução Penal, em seus Artigos $11^{\circ}, 12^{\circ}$ e $41^{\circ}$, estabelece como direito do/da detento/a a assistência material de fornecimento de alimentação suficiente, instalações higiênicas e vestuário (BRASIL, 1984). Assim, o Estado responsabiliza-se, ao privar as pessoas de sua liberdade, por cuidar delas adequadamente. (RUDNICKI, 2011).

Da mesma forma, o Direito Humano à Alimentação Adequada, conforme Leão (2013, p. 11), relaciona-se "com diferentes interesses e diversos aspectos sociais, culturais, políticos e econômicos, razão pela qual sua concepção ainda é assunto debatido por variados segmentos da sociedade, no Brasil e no mundo". Nessa perspectiva, a Segurança Alimentar e Nutricional - SAN visa garantir o

[...] direito de todos ao acesso regular e permanente a alimentos de qualidade, em quantidade suficiente, sem comprometer o acesso a outras necessidades essenciais, tendo como base práticas alimentares promotoras de saúde que respeitem a diversidade cultural e que sejam ambiental, cultural, econômica e socialmente sustentáveis (Artigo $3^{\circ}$, Lei 11.346/2006 - LOSAN).

Ao procurar garantir o acesso permanente, com qualidade e quantidade, Leão (2013) acrescenta que a política de Segurança Alimentar e Nutricional é essencialmente intersetorial, interligada, de modo a potencializar suas ações. Isso significa que cada setor ligado a ela deve desenvolver ações para sua promoção. No caso dos complexos prisionais, o modelo de alimentação carcerária é estabelecido através de diretrizes que buscam, em teoria, proporcionar saúde e bem-estar aos/às detentos/as. No âmbito da alimentação, as comidas preparadas e disponibilizadas nas unidades carcerárias devem atender os padrões específicos de dietas e de higiene na sua preparação e distribuição, estipulados por profissional nutricionista, conforme observado no relatório da Comissão Parlamentar de Inquérito do sistema carcerário (BRASIL, 2009).

Os procedimentos padronizados e operacionais para produção de alimentos em unidades carcerárias comportam os ingredientes, temperos, métodos de cocção, horários das refeições e demais fatores particulares a elas. Um dos principais problemas que atingem as cozinhas nos complexos prisionais é a precariedade das instalações físicas, a falta de suporte técnico e a deficiência de cuidados com processos seguros de produção de alimentos e de comidas. (RIZZO; FONSECA, 2018). De outro modo, tais práticas, quando seguras e adequadas, permitem a realização de refeições com padrões de higiene e segurança alimentar que visam a garantia da qualidade de vida, bem-estar e saúde da comunidade prisional. 
Dessa maneira, percebe-se a existência de disparidades entre os regulamentos legais e a realidade prisional em relação à alimentação. A Resolução $\mathrm{N}^{\circ} 3$, de 5 de outubro de 2017 , que dispõe sobre a prestação de serviços de alimentação e nutrição às pessoas privadas de liberdade e aos/às trabalhadores/as no sistema prisional, no Artigo $7^{\circ}$ aponta que "os cardápios deverão oferecer, no mínimo, cinco porções de frutas, verduras e/ou legumes in natura por dia (400g diárias) nas refeições ofertadas, sendo que as bebidas à base de frutas não substituem a oferta de frutas in natura". (BRASIL, 2017).

Sobre esses aspectos, Rudnicki $(2011,2012)$ observou a insatisfação dos encarcerados em presídios, principalmente quanto à má qualidade dos alimentos e das comidas e, por vezes, a falta de uma das refeições. A saúde dos/das detentos/as é assegurada - ou não -, através da alimentação e demais atividades promovidas no ambiente carcerário, e se configura como obrigatoriedade a ser cumprida pelo sistema presidiário, devido ao desprovimento de liberdade e dever a ser cumprido frente às legislações seguradoras da alimentação adequada supracitadas.

Para a pessoa detida, há também a dependência da aceitação do que é servido como alimento, o que diminui a sua atuação como personagem cidadã. Nesse sentido, a ausência de autonomia conferida aos privados de liberdade deprecia os significados intrínsecos ao ato de comer nas unidades penitenciárias. Assim, inibe-se este conceito da

centralidade da comida como categoria que exprime, além dos horizontes do alimentar e do nutrir, a historicidade capaz de vincular o gosto e a mesa aos sujeitos e suas condições sociais, revelando o mundo da vida cotidiana, as experiências socioculturais que o indivíduo materializa no ato de suas escolhas alimentares. (RIZZO; FONSECA, 2018, p.120).

Nesse contexto, a oferta de alimentos de baixa qualidade pode ser entendida como opressão e/ou descaso, ou, em termos freireanos, de desumanização. No entanto, o real cenário não é apoiado por lei. No âmbito internacional, como direito humano e social, a alimentação é assegurada pelo Pacto Internacional dos Direitos Econômicos, Sociais e Culturais e pela Cúpula Mundial da Alimentação (SOUSA et al., 2019). A minimalidade de recursos concedidos nos complexos prisionais, logo, é contrária ao sancionado, como estipulado no Artigo $20^{\circ}$ das Regras Mínimas da ONU, ao determinar que o Estado deve fornecer ao preso, em horas determinadas, "alimentação de boa qualidade, bem-preparada e servida, cujo valor nutritivo seja suficiente à manutenção de sua saúde e de seu vigor físico". (BRASIL, 2009, p. 199).

Ao estabelecer que a dieta da população prisional deve possuir características de adequação, equilíbrio, controle calórico, moderação e variedade entre os ingredientes que a compõem, os sistemas legislativo e jurídico, como autoridades, determinam o quê, quanto e como será a alimentação dos detentos. A comida, então, torna-se um veículo de exercício de poder e regu- 
lação das formas de viver (SOUSA et al., 2019) e a não disponibilização das estipulações adequadas quanto à alimentação dos detidos significa a desnutrição física, emocional e moral dos/as cidadãos/ãs em cárcere, visto que impacta diretamente em sua sobrevivência como ser social e cultural.

A insuficiência alimentar, como objeto infligidor de opressão aos/às apenados/as, é manifestada através da repetição de determinados ingredientes e pela insuficiência de outros, previstos como ideais para a alimentação carcerária. Isto culmina na privação tanto do prazer ao comer quanto da manutenção fisiológica do organismo humano, ambos potenciais inerentes às funções do alimento. Dessa maneira, ocorre o que Sousa et al. (2019, p. 1671) determinam como regulação dos prazeres da boca: "a negação da cidadania pela comida e o comer no sistema penitenciário".

O desprovimento de sensações positivas no ato de comer, que remetem a vivências e, portanto, possibilitam a identificação entre o comensal e a comida, é recorrente em complexos prisionais. Sobre esse aspecto, Smoyer e Lopes (2017) abordam que o consumo de comida insípida há tempos vem sendo identificado como um atributo punitivo da vida em prisão. Para as autoras, essas práticas punitivas adquirem significados concretos e/ou simbólicos. O primeiro se refere a privações de ordem material e física, enquanto a segunda significa a perda de personalidade, de autonomia, do ser.

Assim, a privação de liberdade é transformada em processo estendido e contínuo de perda, caracterizada por meio de um conjunto de privações: o tempo curto para comer, a pouca interação e socialização permitida entre os/as detidos/as, a observância contínua por parte da segurança e o detrimento da prática da escolha. Nesses espaços, a escassez alimentar como opressão e punição denota o poder alegórico e objetivo do comer para e sobre os que comem. (SMOYER; LOPES, 2017).

Em síntese, a situação da alimentação em complexos prisionais compreende diversos fatores, que, interligados, interferem diretamente na performance do indivíduo que está cumprindo processo penal. A alimentação, como prática de garantia da dignidade humana, surge como potencial sociocultural, pois, por consequência do consumo de comida saudável, adequada, saborosa e em quantidade satisfatória, torna-se possível a manutenção da saúde física e emocional da comunidade carcerária, pelo cumprimento devido das exigências constitucionais e nutricionais, bem como da necessidade de assegurar a saúde pública e proteger a dignidade humana. 


\section{Saberes das experiências na produção de alimentos no complexo prisional de Santa Cruz do Sul}

No tópico anterior, procurou-se demonstrar a comida como direito humano, relacionada com a dignidade e a saúde pessoal e pública através de uma pesquisa bibliográfica e documental. Todavia, no contexto de complexos prisionais, faz-se iminente considerar os espaços em que os alimentos disponibilizados à população carcerária são produzidos e distribuídos. Neste tópico, busca-se apresentar a realidade dos processos produtivos e de distribuição de comida no complexo prisional de Santa Cruz do Sul, assim como identificar os saberes pelas experiências daqueles que a produzem pelo trabalho, enquanto indivíduos e grupo.

O lócus das atividades de extensão do Curso de Gastronomia da Universidade de Santa Cruz do Sul é o presídio regional de Santa Cruz do Sul. O estabelecimento e desenvolvimento do sistema carcerário na referida cidade ocorreu em três momentos históricos, conforme Corrêa (2009, p. 9):

\footnotetext{
Nos primeiros anos da colonização do município [1849], em meados do século XIX, é construída a cadeia municipal. Em 1930, é inaugurado um novo prédio, com mais estrutura, conhecido como "Velho Cadeião", localizado em área central da cidade. No final da década de 1970 é criado o Presídio Regional de Santa Cruz do Sul, na periferia da cidade, que passa a abrigar presos de vários municípios da região.
}

A estrutura atual possui capacidade de engenharia para 166 vagas, distribuídas em quatro galerias (A, B, C, D). Além de duas cozinhas, de espaços administrativos, de serviços especializados em promoção da saúde (enfermaria, assistência social, psicologia, consultório médico e odontológico), fazem parte do complexo salas de aula e de atendimento ao público. No ano de 2005, foi construído um espaço destinado às mulheres detentas, com capacidade para abrigar 48 mulheres em um espaço anexo. Atualmente, conforme dados do Departamento de Segurança e Execução Penal - Superintendência dos Serviços Penitenciários - SUSEPE de março de 2021, o complexo prisional abriga 332 homens e 30 mulheres privadas de liberdade.

A superlotação em complexos prisionais é apenas um dos problemas que atingem o sistema carcerário brasileiro, em geral. Além disso, o Conselho da Comunidade, em visita periódica ao complexo, observou a má qualidade das comidas servidas e o desperdício de alimentos, tanto no decorrer do processo produtivo quanto após a sua distribuição nas galerias. A reação à condição da qualidade dos alimentos concedidos se estabeleceu em forma de protesto recorrente, que consistia no descarte deles através das janelas das galerias, o que contribuiu para a proliferação de roedores e de outros animais que reforçam a insalubridade nas dependências da penitenciária. Essa preocupação, apontada por Diuana et al. (2008), relacionada à disseminação de doenças devido às más condições de higiene, é usual entre especialistas em saúde pública, pelo perigo de ocorrência de surtos de doenças infecciosas - leptospirose, micoses, sarna, parasitoses e infecções bacterianas. 
Assim, a partir de registros dessas demandas quanto à alimentação, segurança alimentar e produção de alimentos no presídio regional de Santa Cruz do Sul, o Conselho da Comunidade as encaminhou ao subprojeto Alimentação e Saúde, vinculado ao Programa Nacional de Reorientação da Formação Profissional em Saúde - PRÓ-SAÚDE da Universidade de Santa Cruz do Sul, com a solicitação de auxílio para minimizar os problemas identificados, conforme já mencionado, de forma a cumprir as estipulações dos Direitos Humanos, especialmente o Direito Humano à Alimentação Adequada (LEÃO, 2013; RUDNICKI, 2011).

Nesse contexto, desde 2018, o grupo de trabalho vinculado ao referido subprojeto tem realizado ações de promoção da saúde, com foco no aprimoramento da qualidade de vida das pessoas que se encontram nesse complexo prisional. Isso é realizado através de capacitações práticas com os cozinheiros quanto a Boas Práticas de Manipulação de Alimentos, visando a melhoria das técnicas de produção, aplicadas com controle higiênico sanitário adequado, como também a redução de desperdícios e melhor aproveitamento dos ingredientes disponíveis, através de cardápios planejados em conjunto com os trabalhadores da cozinha.

Todas as atividades de planejamento, produção, distribuição e limpeza são realizadas por 19 trabalhadores organizados em escalas, nas duas cozinhas do complexo. O escalonamento e a distribuição das tarefas são realizados por um líder, detento, com maior tempo de participação no programa de ressocialização. O perfil desses trabalhadores, cozinheiros homens e apenados, é bem variado, com idade entre 24 e 62 anos, brancos e negros, com ensino fundamental e médio incompletos, provenientes de municípios próximos de Santa Cruz do Sul e sem experiência profissional ou formação técnica para a execução das atividades de produção de alimentos.

Segundo o inquérito do sistema carcerário do Brasil (2009, p. 201), é permitido que os presos produzam parte dos alimentos para seu consumo, otimizando a diminuição dos custos e melhoria na qualidade da comida, além de proporcionar ocupação e remuneração aos mesmos. O trabalho prisional, conforme Fernandes e Ribeiro (2018), apresenta características semelhantes a outras tipologias de trabalho. Essas atividades laborais são realizadas pelos/as prisioneiros/as em conformidade com a política de ressocialização, regulamentada através da Lei de Execução Penal ( $N^{\circ}$ 7210/84). O instrumento legal prevê que, a cada três dias de trabalho, é reduzido um dia de pena do sujeito trabalhador em condição de privação de liberdade, possibilitando a redução de $1 / 3$ da pena prevista.

Conforme Fernandes e Ribeiro (2018, p. 351),

essa legislação exige que, após o acolhimento, o preso passe por uma avaliação, cujo objetivo é destiná-lo para uma oficina de trabalho, educação ou atividade social para promover a sua reintegração social. Essa avaliação é feita por uma equipe multidisciplinar, que é formada por profissionais como médicos, psicólogos, advogados entre outros. Tais técnicos devem discutir cada caso individualmente para propor determinadas atividades como cerne do programa de ressocialização. 
Dessa forma, a rotina de trabalho diário na cozinha inicia-se às 6 horas, para a organização e finalização do café da manhã. Os pães, que são utilizados para o café da manhã e lanche da tarde, são assados diariamente, em média de 800 unidades, geralmente no dia anterior. São pães pré-prontos, moldados e congelados, entregues semanalmente no complexo. As atividades de extensão universitária realizadas no complexo, em conjunto com os trabalhadores da cozinha, permitiram acompanhar o processo referente à preparação dos pães. Constatou-se que apenas um dos detentos é o responsável pela preparação e organização, o qual possui o saber técnico de distribuir os pães congelados em uma assadeira específica e deixá-los em processo de fermentação por 4 a 6 horas, para depois assá-los em forno.

Durante o processo de observação in loco, houve a percepção da má conservação e falta de revisão dos equipamentos destinados à elaboração dos pães. A câmara de fermentação, equipamento no qual os pães são colocados para levedar, não tinha controle de temperatura e nem de umidade, exigindo uma atenção do responsável, principalmente nos dias mais frios, o que lhe exigia outros saberes da experiência cotidiana. $\mathrm{O}$ forno do tipo turbo, profissional e específico para a elaboração de pães e assados em geral, aparentemente em bom estado, não recebia revisão técnica havia, pelo menos, dois anos, e não tinha disponível a função de vapor ${ }^{\mathrm{iii}}$, pois não havia ponto hidráulico nas proximidades. Assim, observou-se que, apesar do profissional responsável não saber fazer pão da forma tradicional, conhece todos os processos técnicos que devem ser realizados para a cocção dos pães pré-moldados e congelados.

Quanto ao café da manhã, ele consiste em dois pães sem recheio, servido com café com leite. Segundo os trabalhadores, rechear aproximadamente 650 pães todos os dias, pela manhã, demandaria tempo e força de trabalho e, consequentemente, poderia atrasar todo o fluxo de produção do almoço. Registrou-se que foi acertado o envio às galerias de potes com doce de frutas ou margarina, conforme disponibilidade do estoque. É da administração dos/as detentos/as a responsabilidade de utilizá-los de acordo com a oferta e preferência. Desse modo, essa refeição geralmente é distribuída nas galerias a partir das 7 horas.

Finalizada e organizada a cozinha, dá-se início às atividades de preparo do almoço. $\mathrm{O}$ feijão preto, que é deixado de molho previamente, é colocado para cozinhar concomitante ao processo de elaboração do café da manhã. O processo de cozimento é realizado na primeira hora, pois não há na cozinha do complexo panela de pressão, portanto, é preciso cozinhar com antecedência para que o grão possa ficar macio. Na sequência, são realizadas outras preparações de acompanhamento, sem planejamento prévio do cardápio, mas em conformidade com o estoque.

Com relação ao cardápio, observou-se que o arroz e o feijão são preparações recorrentes, juntamente com pequena gramatura de carne, outro acompanhamento, salada e uma 
fruta - maçã, banana, laranja ou bergamota. Finalizadas as preparações do almoço do dia, com cuidado, são colocadas sobre um carrinho de quatro rodas as panelas contendo as comidas, que são levadas por um detento até a entrada de cada uma das galerias. A distribuição é realizada por outro detento, o qual não tem contato com os trabalhadores da cozinha e coleta, ao circular no corredor, de cela em cela, os potes pessoais nos quais as comidas são servidas para consumo.

Após o término de atividades concernentes ao preparo e à oferta do almoço, dá-se procedimento à organização do espaço produtivo, para então os trabalhadores iniciarem os preparos do lanche da tarde e do jantar. O primeiro não demanda muito envolvimento para sua produção, pois, na maioria das vezes, consiste em um pão que foi assado em quantidade suficiente para essa refeição no dia anterior, distribuído a partir das 15 horas. O jantar, que é servido a partir das 17 horas, é, na maioria das vezes, uma repetição do que foi servido ao meio-dia, muitas vezes sendo o feijão reaproveitado.

É importante destacar que o envio da dobradinha feijão e arroz todos os dias, conforme relato do cozinheiro responsável, ocorre em virtude da baixa variedade, qualidade ou preferência por determinados acompanhamentos disponibilizados e, também, por ser de mais fácil combinação com outros alimentos que são preparados pelos/as detentos/as nas celas/galerias, como é o caso das carnes. Segundo relato, essa é uma prática muito comum no complexo. Os alimentos são trazidos pelos familiares, nas quartas-feiras, dia de visita, e armazenados e preparados na própria cela, a partir do uso de um fogão elétrico. É válido abordar que tal prática, embora permita variabilidade e maior conexão afetiva com o alimento, por acontecer em ambiente impróprio para cocção de refeições, apresenta-se como risco à saúde. Esse é um dos fatores a ser considerado para a concretização do acesso e da oferta de comida de qualidade, previstos em lei aos sujeitos privados de liberdade.

As experiências de trabalho coletivo e extensionista junto ao complexo prisional permitem aferir sobre outros aspectos diversos, que serão desenvolvidos a seguir. O primeiro se refere à infraestrutura da cozinha. No inquérito do sistema carcerário brasileiro, a Comissão Parlamentar identificou o desvio do atendimento às normas da vigilância sanitária das cozinhas, por serem "mal projetadas, pequenas, sujas e mal ventiladas, sem manutenção rotineira, além de não dispor de nutricionistas". (BRASIL, 2009, p. 456). Quanto ao presídio regional de Santa Cruz do Sul, observou-se a mesma realidade nestes ambientes: pouca ventilação, porém boa iluminação, considerando que uma cozinha deve ter boas condições de iluminação e circulação de ar. Os equipamentos e utensílios para a execução das preparações apresentavam estado visivelmente danificado, evidenciando a depreciação decorrente do longo tempo de uso. Contudo, percebeu-se o cuidado dos trabalhadores com os processos de manutenção e limpeza.

Quanto à disponibilidade de insumos para a elaboração das refeições, buscou-se compreender o desenvolvimento das atividades em sua totalidade, desde o recebimento das mercadorias, a organização do estoque no almoxarifado e o processo de criação/planejamento da 
produção. Quanto ao planejamento, constatou-se que as preparações eram realizadas sem o acompanhamento de profissional especializado em alimentação e nutrição. Esse aspecto não deve ser relativizado, uma vez que foi evidenciado, no relatório da Comissão Parlamentar de Inquérito do sistema prisional (BRASIL, 2009) e na política de Segurança Alimentar e Nutricional (LEÃO, 2013), a participação e o acompanhamento de profissionais qualificados na produção de alimentos.

Uma das principais manifestações dos consumidores (detentos/as e profissionais da segurança) era justamente esse tipo de problema - de invariabilidade de alimentos servidos no mesmo dia -, como relatou o diretor do complexo, conforme registro no diário de campo (2019): "tinha ovo frito e omelete no café da manhã, ovo cozido e omelete novamente no almoço e ovo na janta". A falta de planejamento e organização de um cardápio e de produção incitaram práticas de descarte por parte dos detentos, o que não somente preocupa especialistas em saúde pública como enfatiza a inadequação das práticas alimentares prisionais em relação aos Direitos Humanos (LEAL, 2013; RUDNICKI, 2011).

No mesmo diário, foram registrados todos os insumos recebidos a partir da análise dos romaneios de entrega. Foi observado que os itens de hortifruti - legumes e verduras: cebola, tomate, alho, pimentão, batata, batata doce, beterrabas, cenouras, chuchu, couve-flor, moranga, repolho; de frutas: maçã, banana, laranja; e de ervas frescas: salsa, louro e manjerona - eram entregues todas as segundas, quartas e sextas-feiras, provenientes de fornecedores da cidade.

Quanto aos alimentos não perecíveis, observou-se que não há uma quantidade regular de insumos enviada pela central de distribuição da Superintendência de Serviços Penitenciários (Susepe) para a produção das refeições e o planejamento do cardápio. O desrespeito ao Direito Humano à Alimentação Apropriada também ficou evidenciado quando analisada a quantidade de carnes - bovina de segunda, suína, frango, salsicha e linguiça/salsichão recebida, produzida e destinada aos detentos, que é de 50 gramas de proteína crua por pessoa por dia, isto é, 25 gramas por almoço e janta.

A partir dessa realidade, estabeleceu-se a pertinência de mudança do cenário vigente quanto à produção alimentícia, para a oferta de comida adequada e digna na unidade prisional específica, atentando para planejamento, organização de estoque e a qualificação dos cozinheiros, assim como para a percepção deles quanto à tarefa desempenhada. Deste modo, observandose a necessidade de aprendizados pelos presidiários, desenvolveram-se atividades de formação e capacitação, uma vez por semana, quanto à aplicação de procedimentos técnicos e dicas de produção, principalmente relacionados ao aproveitamento integral dos alimentos, à aplicação de técnicas de cortes e cocção e incorporação de preparações que visem o melhor aproveitamento dos insumos disponíveis no almoxarifado. Além disso, trabalhou-se o armazenamento correto dos alimentos, para que haja seu aproveitamento completo. 
Quanto ao trabalho na produção de alimentos no presídio regional de Santa Cruz do Sul, faz-se necessário ressaltar que se configura de maneira dualista: através da ocupação/ produtividade enquanto afastamento da realidade prisional vivida nas galerias e possibilidade de humanização e de ressocialização após vida no cárcere, com subordinação às condições trabalhistas. Contudo, elas podem ser exploratórias ao se trabalhar "em condições precárias, sem direitos ou mesmo pagamento [...]", como revelado por Fernandes e Ribeiro (2018, p. 350 ), em vista do caráter sobretudo remidor da pena que o trabalho adquire em cenários de unidades penitenciárias.

O trabalho, entretanto, é educativo em si. A relação existente entre trabalho e educação pode ser vista como uma ferramenta para a mobilidade e desenvolvimento social, de modo a possibilitar ao/à trabalhador/a a qualificação necessária para obter ou manter seu emprego, mas que não lhe garante a formação social para a vida. A visão formativa do trabalho e da educação deve ser encarada a partir do que Marx (2008) chama de ação humanizadora, realizada com o desenvolvimento das diferentes potencialidades que são apresentadas pelo ser humano.

O binômio da educação e trabalho, no contexto prisional, possibilita a aquisição de saberes visando a qualificação e a ressignificação do espaço do cárcere, assim como a realização de tarefas de modo eficiente e proveitoso quanto ao aproveitamento integral dos alimentos, a redução de desperdícios e a melhora da qualidade das refeições servidas. Segundo Freire (1996), o ato de educar está diretamente relacionado a humanizar. Nesse pensamento, a educação pode ocorrer tanto em contexto formal quanto em não formal, como no trabalho.

É possível observar diversos processos educativos, muitas vezes experienciados por trabalhadores apenados desses complexos prisionais, que podem proporcionar significativas modificações quanto às suas concepções acerca das vivências e relações de/com o trabalho. Parte-se da compreensão do trabalho como possibilidade de educação/emancipação social e ressocialização desses sujeitos privados de liberdade, para tratar a educação como estratégia de qualificação de mão de obra para o trabalho, de tal forma que o indivíduo possa ter sua capacidade produtiva maximizada durante a privação de sua liberdade (CARVALHO, 2016).

As atividades realizadas conjuntamente com os trabalhadores da cozinha do complexo prisional visibilizaram saberes populares, isto é, conhecimentos provenientes de práticas do cotidiano, que, articulados com as experiências desenvolvidas no trabalho, evidenciam uma apropriação de saberes - conhecimentos metodicamente adquiridos (MORETTI; CORNELI, 2018), associados às rotinas específicas aprendidas ao longo de atividades desenvolvidas no setor. Os saberes técnicos, por sua vez, advindos da experiência com as estudantes vinculadas ao projeto e relacionados à produção de alimentos, se configuram como oportunidades de ampliação de suas capacidades laborais e consequente produção, que, em situação de cumprimento de pena, tem o potencial para transformar e possibilitar a sua ressocialização na vida após o cárcere pela humanização. 
O trabalho na cozinha desvela uma nova configuração de identidade social e profissional objetiva, em vista da realização pessoal possível através das aptidões desenvolvidas enquanto sujeito produtor e criador em cárcere. Os registros permitem aferir que os cidadãos, nessa condição específica, mediante aquisição de conhecimentos e aplicação de processos culinários, pela atuação como cozinheiros da penitenciária, planejavam efetivá-los, como prática corriqueira e profissional, tanto no âmbito do lar quanto num potencial estabelecimento de empreendimentos próprios no ramo da alimentação. Essas observações evidenciam os planos para o pós-cárcere, pela inclusão, no relato dos cozinheiros, do desejo de obterem formação qualificada, técnica ou superior em Gastronomia. Dessa forma, é pertinente destacar o papel social que a gastronomia assume ao contribuir nos processos de ressocialização desses sujeitos em privação de liberdade.

Nesse sentido, o papel desempenhado pelos cozinheiros das unidades carcerárias deve receber atenção especial, pois tais espaços, além de proporcionarem o ambiente para habilitação, mediante organização e práticas ideais, para o ato de cozinhar com sucesso, também tornam possível uma identificação ao lugar como à parte da realidade insalubre e superlotada das galerias, e que possibilita a sua ação enquanto seres trabalhadores.

A conexão positiva com a cozinha permite aos trabalhadores apenados a criação de preparações novas, embora específicas, mas que, por sua vez, geram motivação para adquirir mais conhecimento no processo educativo diário. A partir desse contato didático semanal, a comida foi percebida como dispositivo de memória social e afetiva, na qualidade de eclodir experiências de comensalidade anteriores à reclusão para cumprimento de pena, podendo ser evocada nesse local de trabalho e capacitação, configurando-se como "um veículo de expressão e renovação de vínculos externos, pois os alimentos, muito além de nutrir, significam e comunicam". (SOUSA et al., 2019, p. 1672).

O trabalho prisional, no entanto, apesar de ter como objetivo direto a ressocialização, representa uma ameaça à dignidade humana, visto que a alienação sistemática causada pelo trabalho e a exploração consequente são pertinentes enquanto objetos usados como promessa da remissão da pena. De fato, o labor permite que o ser humano reproduza a sua existência e tome consciência de si e de seu valor. Logo, o trabalho como prática dignificadora se contrapõe aos meios articulados de exploração sobre o trabalhador, que é configurada no valor pago aos trabalhadores encarcerados, que, de tão mínimo, pode ser considerado ilustrativo ou até mesmo um disfarce de escravidão (FERNANDES; RIBEIRO, 2018).

De tal forma, o trabalho em prisão como prática para a liberdade é constituído, pelos sistemas que o regem, como instrumento para salientar a dependência quase absoluta imposta sobre o/a apenado/a, diminuindo diretamente a eficácia do papel da ressocialização na vida pós-cárcere. Embora o trabalho seja instituído e admitido para cidadãos em situação prisional, assim como a alimentação, os modos de operação sobre a vida e dignidade da pessoa através 
dessa atividade empoderadora delimitam seu desempenho pessoal entre as grades, bem como livre delas.

Ao longo deste tópico, procurou-se discorrer sobre a relação entre alimentação e saberes da experiência no trabalho percebidos nos processos de produção na cozinha de uma unidade prisional. Nesse viés, buscou-se identificar, descrever e refletir a respeito dos saberes e experiências - prévios ou adquiridos durante a prática educativa do trabalho - dos cozinheiros na elaboração das comidas na penitenciária regional de Santa Cruz do Sul. O efeito do trabalho didático, nessa situação, ultrapassa o produto - a comida - entregue aos detentos: gera, em teoria, aptidão para nova sociabilidade após período em cárcere.

Nesse sentido, a alimentação é constituída como causa e consequência, respectivamente: a concessão da comida prisional produzida por detentos e o retorno à liberdade com qualificação, para eles, assim, ter segurança econômica e reduzir a probabilidade de acharem-se em situação de vulnerabilidade social. Os sujeitos em cárcere dignificam-se, então, enquanto trabalhadores/as, reconhecendo-se no processo (MARX, 2008), assim como através da disponibilidade de comida ideal, digna e adequada, conforme parâmetros constitucionais e de políticas como o Direito Humano à Alimentação Adequada, viabilizam a dignidade dos demais apenados na unidade prisional em que atuam como seres produtivos.

\section{Considerações finais}

Alimentar-se é uma das principais necessidades biológicas do ser humano. O debate quanto à alimentação em complexos prisionais, que carece de estudos e atividades extensionistas, torna-se apropriado por abranger diversos fatores, sejam materiais, emocionais, físicos, sociais, morais e de poder.

Ao longo do texto, privilegiou-se apresentar a realidade dos processos de preparo e distribuição da comida no complexo prisional, considerando a relação entre saberes e as experiências do/no trabalho. Observou-se que o cenário do preparo de alimentos é constituído em cozinhas com problemas de estrutura, planejamento e gestão, falta e/ou baixa qualidade de equipamentos, de qualificação da equipe de cozinheiros e de acompanhamento de profissionais especializados - nutricionistas.

Através da abordagem da alimentação em complexos prisionais na perspectiva dos Direitos Humanos, em especial ao Direito Humano à Alimentação Adequada, percebeu-se a comida - seja produção ou produto - como canal de opressão e dominação, nos contextos de consumo desigual, distribuição inadequada e trabalho explorado. O primeiro caso é entendido pela interpretação da comida recebida, assim como pela carência de manutenção da saúde física e do bem-estar dos/as consumidores/as apenados/as. No mesmo ínterim, a exploração laboral prejudica a performance social dos indivíduos produtivos, devido às condições indignas 
e inadequadas de trabalho e remuneração e sem suporte qualificado.

Dessa forma, pertinente à questão da qualidade da comida ofertada, estabelecem-se conjunturas quanto aos saberes da experiência, o trabalho e o potencial de ressocialização neste ambiente, com ênfase nos apenados permitidos a desempenhar as atividades de produção de alimentos em unidades penitenciárias. A partir disso, verifica-se a necessidade de que esse segmento receba maior atenção, por parte do Estado, quanto ao cumprimento das políticas públicas voltadas ao Direito Humano à Alimentação Adequada.

Quanto à demanda da produção de alimentos dignos, saudáveis e de máximo aproveitamento, a partir da prática educativa do trabalho, houve o reconhecimento e aprimoramento do potencial produtivo e saberes dos cozinheiros em situação de privação de liberdade, que, em teoria, podem ser garantidos através da política de ressocialização, se incentivados de maneira afirmativa. Nesse ínterim, a exploração da força de trabalho carcerária deprecia o princípio dignificador do trabalho, da mesma forma que a oferta de alimentação inadequada oprime a dignidade da pessoa detenta.

Cabe destacar alguns dos aspectos proporcionados pela experiência de extensão aos/às estudantes ligados/as ao subprojeto Alimentação e Saúde, vinculado ao Pró-Saúde/Unisc, tais como o caráter social, humanizador e educacional da mesma. O papel da tríade ensino, pesquisa e extensão, na qualificação dos/das estudantes e profissionais formados/as, é reforçado através da vivência e da partilha com demais agentes educativos em si e em conjunto, pela troca de saberes, na produção das comidas. Ao cozinhar, os atores ocupam o papel de protagonistas, sentindo-se valorizados e propícios a refletirem sobre a sua realidade.

A culinária, enquanto prática de bem-estar social, manifesta-se como uma possibilidade educativa de sujeitos privados de liberdade, tanto por parte dos produtores da alimentação carcerária quanto para aqueles que recebem alimento saudável, suficiente e digno, pela afirmação individual e coletiva, e a promoção da saúde pública desse grupo. Assim, há o encontro dos principais saberes populares e da experiência, no processo de ser mais humano, como diria Paulo Freire (1996), realizando sua vocação ontológica antes negligenciada pela alienação dos sujeitos.

\section{Referências}

BRASIL. Emenda Constitucional n⿳0 90, de 15 de setembro de 2015. Dá nova redação ao art. $6^{\circ}$ da Constituição Federal, para introduzir o transporte como direito social. Brasília, DF, 2015. Disponível em: http://www.planalto.gov.br/ccivil 03/constituicao/Emendas/Emc/emc90.htm. Acesso em: 18 jun. 2021. 
BRASIL. Lei no 7210, de 1984. Lei de Execução Penal. Disponível em: http://www.planalto.gov.br/ccivil_03/leis/17210.htm. Acesso em: 18 maio 2021.

BRASIL. Câmara dos Deputados. Comissão Parlamentar de Inquérito do Sistema Carcerário. CPI do sistema carcerário. Brasília: Câmara dos Deputados, Edições Câmara, 2009. Disponível em:http://bd.camara.gov.br/bd/bitstream/handle/bdcamara/2701/cpi_sistema_carcerario.pdf. Acesso em: 08 fev. 2021.

BRASIL. Lei n. 11.346, de 15 de setembro de 2006. Cria o Sistema Nacional de Segurança Alimentar e Nutricional - SISAN com vistas em assegurar o direito humano à alimentação adequada e dá outras providências. Diário Oficial da União, Brasília, DF, 18 set. 2006. Disponível em: http://www4.planalto.gov.br/consea/comunicacao/noticias/2016/ setembro/ losan-e-indispensavel-a-realizacao-de-direitos-consagrados-na-constituicao-federal. Acesso em: 08 fev. 2021.

DIUANA, Vilma et al. Saúde em prisões: representações e práticas dos agentes de segurança penitenciária no Rio de Janeiro, Brasil. Cadernos de Saúde Pública, [S.L.], v. 24, n. 8, p. 1887-1896, ago. 2008. FapUNIFESP (SciELO). Disponível em: https://www.scielo.br/ $\mathrm{j} / \mathrm{csp} / \mathrm{a} / \mathrm{tT7S} 57 \mathrm{RfW} 5 \mathrm{LyGCtDZTsnpxK/?lang=pt \# .} \mathrm{Acesso} \mathrm{em:} 04$ jun. 2021.

CARVALHO, O. F. A educação que leva ao trabalho - o trabalho que leva à escola: superando a dicotomia entre educação e trabalho. Cad. CEDES, Campinas, v. 36, n. 98, p. 79-97, abr. 2016.

CORRÊA, Márcia Maribel. Perfil do Encarcerado do Presídio Regional de Santa Cruz do Sul. 2009. 158 f. Dissertação (Mestrado) - Curso de Programa de Pós-Graduação em Desenvolvimento Regional, Universidade de Santa Cruz do Sul, Santa Cruz do Sul, 2009.

FERNANDES, Paula Cristina de Moura; RIBEIRO, Ludmilla Mendonça Lopes. Sentidos do trabalho prisional: uma revisão da literatura. Textos \& Contextos, Porto Alegre, v. 17, n. 2, ago./dez. 2018. p. 346-362.

FERNANDES, Mônica Abranches. Trabalho comunitário: uma metodologia para ação coletiva e educativa da extensão universitária em comunidades. In: MENEZES, Ana Luisa Teixeira; SÍVERES, Luiz (Orgs.). Transcendendo Fronteiras: A contribuição da extensão das instituições comunitárias de ensino superior. Santa Cruz do Sul: EDUNISC, 2011.

FREIRE, Paulo. Pedagogia da Autonomia: saberes necessários à prática educativa. São Paulo: Paz e Terra, 1996. 
FREIRE, Paulo. Extensão ou comunicação? 17. ed. Rio de Janeiro: Paz e Terra, 2015.

LEÃO, Marília (org.). O direito humano à alimentação adequada e o sistema nacional de segurança alimentar e nutricional. Brasília: Abrandh, 2013.

MARX, Karl. O Capital. 3. ed. Bauru, SP: EDIPRO, 2008.

MENESES, Ana Luisa T.; MORETTI, Cheron Z. Aprendendo com os Guarani: geocultura através do ensino, pesquisa, extensão na universidade comunitária. Sinergias Diálogos educativos para a Transformação Social, v. 6, p. 25-36, 2018.

MORAES, Roque; GALIAZZI, Maria do Carmo. Análise Textual Discursiva. 3. ed. Ijuí: Editora Unijuí, 2016.

MORETTI, Cheron Zanini; CORNELI, Cristiane. Saberes populares, conhecimentos científicos: as mulheres na pedagogia da alternância. Revista de Comunicação Científica, Juara, v. 3, n. 1, p. 6-22, jul./dez. 2018.

OLIVEIRA, Rita de Cássia Magalhães de. (Entre) Linhas de uma pesquisa: o diário de campo como dispositivo de (in)formação na/da abordagem (auto)biográfica. Revista Brasileira de Educação de Jovens e Adultos, Salvador, v. 2, n. 4, p. 69-87, 2014. Disponível em: https://www.revistas.uneb.br/index.php/educajovenseadultos/ article/view/1059. Acesso em: 2 jun. 2021.

OLIVEIRA, Maria Marly de. Como fazer pesquisa qualitativa. 8. ed. Petrópolis: Vozes, 2020.

RIZZO, Tamiris Pereira; FONSECA, Alexandre Brasil Carvalho da. Entre as grades: diálogos entre a educação popular e a promoção da alimentação saudável com adolescentes em cumprimento de medida socioeducativa. Rev. Ed. Popular, Uberlândia, v. 17, n. 2, p. 114-130, maio/ago. 2018.

RUDNICKI, Dani; PASSOS, Gabriel Borrea dos. A Alimentação das presas na penitenciária feminina Madre Pelletier. Tempos da Ciência, São Paulo, v.19, n. 37, p. 107$123,2012$.

RUDNICKI, Dani. Comida e direitos humanos no Presídio Central de Porto Alegre. Revista Direito GV, São Paulo, v. 7, n. 2, p. 515-538, jul./dez. 2011.

SMOYER, Amy B.; LOPES, Giza. Hungry on the inside: Prison food as concrete and symbolic punishment in a women's prison. Punishment \& Society, v. 19, n. 2, p. 240-255, 2017. 
SOUSA, Luciana Maria Pereira de et al. Regime da escassez: a alimentação no sistema penitenciário feminino. Ciência \& Saúde Coletiva, [S.L.], v. 25, n. 5, p. 1667-1676, maio 2020. FapUNIFESP (SciELO).

UNICEF. Declaração Universal dos Direitos Humanos. Disponível em:

https://www.unicef.org/brazil/declaracao-universal-dos-direitos-humanos. Acesso em: 4 maio 2021.

VILLAS BÔAS, Regina Vera; SOARES, Durcelania da Silva. O direito humano à alimentação adequada: interdimensionalidade, efetividade, desenvolvimento humano e dignidade da pessoa humana. Revista de Direitos Humanos e Efetividade, v. 6, n. 2, p. 19-38, jul./dez. 2020.

\footnotetext{
Notas

${ }^{\mathrm{i}}$ Esta pesquisa contou com o apoio da FAPERGS - Projeto ARD 21/2551-0000652-8.

ii Art. 80. Haverá, em cada comarca, um Conselho da Comunidade composto, no mínimo, por 1 (um) representante de associação comercial ou industrial, 1 (um) advogado indicado pela Seção da Ordem dos Advogados do Brasil, 1 (um) Defensor Público indicado pelo Defensor Público Geral e 1 (um) assistente social escolhido pela Delegacia Seccional do Conselho Nacional de Assistentes Sociais. (BRASIL, Lei N7210/84).

iii A função de elaboração de pães do tipo francês é importante, pois traz maciez ao miolo e crocância à casca.
} 